\title{
Validated Hptlc Method for Simulteneous Determination of Ceftriaxone Sodium and Sulbactam Sodium in Combined Dosage Form
}

\author{
Mr. Sanjay S. Malgundkar ${ }^{1}$, Dr. Saira Mulla ${ }^{2} *$ \\ Shri Jjt University, Vidyanagari, Churu-Jhunjhunu Road, Chudela, \\ District-Jhunjhunu, Rajasthan-333001
}

\begin{abstract}
This paper describes a new simple, accurate and precise HPTLC method for simultaneous estimation Ceftriaxone sodium and Sulbactam sodium as bulk and dry powder for injection in combined dosages form. In this method, the densitograms were developed using mobile phase of Chloroform: Ethyl alcohol: Diethyl amine: Water (12: 7:1:0.4 v/v). Aluminum plate coated with the silica Gel $60 F_{254}$ as stationary phase was used. Densitometric evaluation of the separated bands was performed at $285 \mathrm{~nm}$. The Rf values of Ceftriaxone sodium and Sulbactam sodium are $0.31 \pm 0.01$ and $0.58 \pm$ Respectively.

The method was linear over the concentration range of $400 \mathrm{ng}$ to $1200 \mathrm{ng} / \mathrm{spot}$ and $300 \mathrm{ng}$ to 7000 $\mathrm{ng} / \mathrm{spot}$ of ceftriaxone sodium and Sulbactam sodium respectively. Precision of the method was evaluated by calculating RSD for peak response by inerday and intraday analysis. The results were Ceftriaxone sodium: Inter day RSD of peak response $0.88 \%$ Intraday RSD $1.34 \%$ and for Sulbactam sodium Interday RSD of peak response $1.54 \%$ and Intraday RSD $1.22 \%$. Accuracy was determined in terms of percentage recovery at three concentration levels for Ceftriaxone sodium $=R S D 1.92 \%, 1.84 \%$ and $0.66 \%$ and for sulbactam sodium = $1.69 \%, 1.79 \%$ and $0.66 \%$ respectively. Specificity was proved by spectral analysis of cetfriaxone sodium and sulbactam sodium and overlaying the standard spectra and sample spectra respectively. There is no any interference of mobile phase and diluents at the RF values of Ceftriaxone sodium and sulbactam sodium. Validation was done in accordance with the ICH Guidelines.
\end{abstract}

Key words: High performance thin layer chromatography, microgram, nano gram, Ceftriaxone sodium and Sulbactam sodium. yl)(methoxyimino)acetyl]amino]-3-[[(2- methyl-6-oxido-5-oxo-2,5-dihydro-1,2,4-triazin-3yl)sulphanyl]methyl]-8-oxo-5-thia-1- azabicyclo [4.2.0] oct-2-ene-2-carboxylate 3.5 hydrate. It is Semisynthetic product derived from a fermentation product. Molecular formula of ceftriaxone sodium is $\mathrm{C}_{18} \mathrm{H}_{16} \mathrm{~N}_{8} \mathrm{Na}_{2} \mathrm{O}_{7} \mathrm{~S}_{3}, 3 \frac{1}{2} \mathrm{H}_{2} \mathrm{O}$. Molecular weight of Ceftriaxone sodium is 662.0 and CAS number is 104376-79-6. Ceftriaxone sodium is a third-generation cephalosporin antibiotic. Like other third-generation cephalosporins, it has broad-spectrum activity against Gram-positive and Gram-negative bacteria. In most cases, it is considered to be equivalent to cefotaxime in terms of safety and efficacy.

Ceftriaxone sodium is often used (in combination, but not direct, with macrolide and/ or aminoglycoside antibiotics) for the treatment of community-acquired or mild to moderate health careassociated pneumonia. It is also a choice drug for treatment of bacterial meningitis.In pediatrics; it is commonly used in febrile infants between 4 and 8 weeks of age who are admitted to the hospital to exclude sepsis. It has also been used in the treatment of Lyme disease, typhoid fever, and gonorrhea. Ceftriaxone sodium is freely soluble in water, sparingly soluble in methanol, very slightly soluble in anhydrous ethanol.

Sulbactam sodium is chemically sodium $(2 S, 5 R)$-3, 3-dimethyl-7-oxo-4-thia-1-azabicyclo [3.2.0] heptane-2carboxylate 4, 4-dioxide. Semi-synthetic product derived from a fermentation product.

Sulbactam sodium is being used as Beta-lactam antibacterial. Molecular weight is 255.2 and CAS Number is 69388-84-7. Sulbactam sodium is Semi-synthetic product derived from a fermentation product. It is freely soluble in water, sparingly soluble in ethyl acetate, very slightly soluble in ethanol (96 per cent). It is freely soluble in dilute acids.

Literature survey reveals that the several analytical methods have been reported for estimation of Ceftriaxone sodium and Sulbactam sodium as an individual drug substance and in the combination drug by High performance liquid chromatography and UV-VIS spectrophotometric method.

A simple, accurate and precise HPTLC method for simultaneous estimation Ceftriaxone sodium and Sulbactam sodium in dry powder injection manufactured in the combined dosages form has been developed. 
<smiles>CO/N=C(\C(=O)N[C@H]1C(=O)N2C(C(N)=O)=C(CSc3nc(=O)c(O[Na])nn3C)CS[C@H]12)c1csc(N)n1</smiles>

(a)

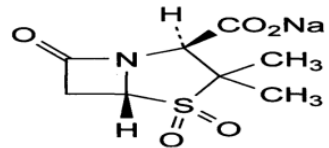

(b)

Figure 1. Structure of Ceftriaxone sodium (a) and Structure of Sulbactam sodium (b)

\section{Materials and Methods}

\subsection{Chemicals and Reagents}

Working Standard of Ceftriaxone sodium and Sulbactam sodium were provided by Aurobindo Pharma Ltd through Mr. Vikrant Tamse-Senior Manager Purchase as Gererous gift samples for study. Dry powder injection samples were procured from the market. All other reagents used were of analytical grade.

\subsection{Instrumentation}

In this paper, information pertaining to the analytical method validation and evaluation of combination drug has been provided. HPTLC is superior analytical technique in respect of the time and cost of analysis.

HPTLC technique comprises offline stages. These stages are independent of each other. This includes application of samples on the precoated plate, scanning of the developed plates and densitogram etc. The most important features of this technique is to analyse the samples containing multi components in single analysis, application of large number of samples and series of samples by spray techniques. A variety of mobile phases can be developed by using different solvents at different compositions. The mobile phase is being evaporated before the detection step. Application of samples and standard solution is simultaneously being done on the same plate.

CAMAG automatic TLC sampler 4 (ATS4) connected with the win CATS 4 software, CAMAG TLC SCANNER, Integrator controlled by win CATS4 Software, CAMAG twin trough glass chamber with stainless steel lid. Precoated silica Gel $60 \mathrm{~F}_{254}$ on aluminium sheets.

In a $20 \times 10 \mathrm{~cm}$ twin trough glass chamber (Make: CAMAG), a linear ascending chromatographic development was carried out by using mobile phase, Chloroform: Ethyl alcohol: diethyl amine: water in the ratio $(12: 7: 1: 0.4 \mathrm{v} / \mathrm{v})$. The chamber was saturated for 20 minutes. After development, TLC plate was dried in a current of hot air with the help of hair dryer and dried on a CAMAG hot plate at $120^{\circ} \mathrm{C}$ for 5 minutes. A deuterium lamp was used in the UV range of 190 to $400 \mathrm{~nm}$ as a source of radiation. A slit dimension was 6.00 x $0.45 \mathrm{~mm}$, micro, scanning speed was $20 \mathrm{mms}^{-1}$ and data resolution at $100 \mu \mathrm{m} / \mathrm{step}$. Sample was spotted on the silica gel $60 \mathrm{~F}_{254}$ TLC plate by using CAMAG automatic TLC sampler-4 (ATS). The plates were developed in the CAMAG TLC chamber upto $80 \mathrm{~mm}$. The contents of ceftriaxone sodium and Sulbactam sodium were evaluated by comparing the peak areas with linear regression.

\section{Standard Solution Preparation}

$10 \mathrm{mg}$ of Ceftriaxone sodium and $10 \mathrm{mg}$ of Sulbactam sodium standards were accurately weighed and transferred to separate $10 \mathrm{~mL}$ volumetric flasks. $2 \mathrm{~mL}$ of Methanol was added and sonicated for 5 minutes to dissolve. Then diluted to $10 \mathrm{~mL}$ with methanol (Stock solution 1 and stock solution 2 for ceftriaxone sodium and Sulbactam sodium respectively). $1 \mathrm{ml}$ from stock solution 1 and $5 \mathrm{~mL}$ from stock solution 2 were pipetted out in two separate volumetric flasks and diluted to $10 \mathrm{~mL}$ with methanol to obtain the concentration of $0.1 \mathrm{mg} / \mathrm{mL}$ and $0.5 \mathrm{mg} / \mathrm{mL}$ of standard ceftriaxone sodium and Sulbactam sodium respectively.

\section{Sample Solution Preparation}

Label claim of Ceftriaxone sodium and Sulbactam sodium in the combined dry powder injection in one unit is $1000 \mathrm{mg}$ and $500 \mathrm{mg}$ respectively. To determine the content, 10 vial units were individually weighed. An average weight was recorded. Dry powder from all vials was mixed together to make a pooled sample. A sample weight equivalent to $1000 \mathrm{mg}$ of ceftriaxone and $500 \mathrm{mg}$ of sulbactam was weighed in $10 \mathrm{ml}$ volumetric flask. 2 
$\mathrm{mL}$ of Methanol was added and sonicated for 5 minutes to dissolve. Then diluted to $10 \mathrm{~mL}$ with methanol to obtain the concentration of $1 \mathrm{mg} / \mathrm{mL}$ and $0.5 \mathrm{mg} / \mathrm{mL}$ of Ceftriaxone and Sulbactam respectively.

\subsection{Validation of analytical method}

\section{Results and Discussions}

An analytical method developed was validated for the validation parameters Specificity, linearity, accuracy, precision, LOD, LOQ and Robustness.

\subsubsection{Specificity}

A specificity was determined by analyzing reference standards, samples, diluent and mobile phase being used to verify the interference of mobile phase and diluents during analysis. There was no any interference of Mobile phase and diluent at the $R F$ values of Ceftriaxone sodium and Sulbactam sodium. The separated bands of Ceftriaxone sodium and Sulbactam sodium were confirmed by comparing $R F$ values. The RF values of Ceftriaxone sodium and Sulbactam sodium were 0.29 and 0.54 respectively. UV spectra recorded at Peak start ( S) Peak apex(M) and peak end(E) of both the drugs were also overlapped on each other and were matching.

\subsubsection{Accuracy}

In method validation, accuracy was being determined by the percentage recovery.

The known concentrations of the samples were spiked with the standard ceftriaxone and sulbactam in the concentrations of $240 \mathrm{ng}, 300 \mathrm{ng}$ and $360 \mathrm{ng}$ of ceftriaxone sodium and $1200 \mathrm{ng}, 1500 \mathrm{ng}$ and $1800 \mathrm{ng}$ of sulbactam sodium at $80 \% 100 \%$ and at $120 \%$ level with respect to the sample concentration. The spiked samples were analysed by following the proposed analytical method. The percentage recovery was calculated and was in the range of $100.78 \%$ to $101.92 \%$ for Ceftriaxone sodium and $100.74 \%$ to $101.82 \%$ for Sulbactam sodium respectively. The detail results are tabulated as under:

Table 1. : Percentage Recovery of Ceftriaxone sodium $(\mathbf{n}=3)$

\begin{tabular}{|c|c|c|c|c|}
\hline $\begin{array}{c}\text { Sr. } \\
\text { No. }\end{array}$ & $\begin{array}{c}\text { Amount of std. Ceftriaxone } \\
\text { sodium added in ng }\end{array}$ & $\begin{array}{c}\text { Amount of std. ceftriaxone sodium } \\
\text { recovered in ng }\end{array}$ & \% Recovery & $\begin{array}{c}\text { \% Relative } \\
\text { standard Deviation }\end{array}$ \\
\hline 1 & 240 & 244.60 & 101.92 & 1.92 \\
\hline 2 & 300 & 302.43 & 100.81 & 1.84 \\
\hline 3 & 360 & 362.80 & 100.78 & 0.60 \\
\hline
\end{tabular}

Table 2: Percentage Recovery of Sulbactam sodium $(\mathbf{n}=3)$

\begin{tabular}{|l|l|l|l|l|}
\hline $\begin{array}{c}\text { Sr. } \\
\text { No. }\end{array}$ & \multicolumn{1}{|c|}{$\begin{array}{c}\text { Amount of std. Sulbactam } \\
\text { sodium added in ng }\end{array}$} & $\begin{array}{c}\text { Amount of std. Sulbactam sodium } \\
\text { recovered in ng }\end{array}$ & $\begin{array}{c}\text { \% Recovery Relative } \\
\text { standard Deviation }\end{array}$ \\
\hline 1 & 1200 & 1211.04 & 100.74 & 1.69 \\
\hline 2 & 1500 & 1513.8 & 100.92 & 1.79 \\
\hline 3 & 1800 & 1832.76 & 101.82 & 0.66 \\
\hline
\end{tabular}

\subsubsection{Precision}

The interday and intraday precision of the method were estimated by performing six determinations of Ceftriaxone sodium and Sulbactam sodium standard solutions. The analysis was carried by referring the developed method. Analytical results obtained are tabulated as under:

Table 3: Precision for the Ceftriaxone sodium $(n=6)$

\begin{tabular}{|l|l|l|l|}
\hline \multirow{2}{*}{$\begin{array}{l}\text { Conc. of the Ceftriaxone sodium } \\
\text { ng/ band) }\end{array}$} & \multicolumn{1}{|c|}{ Inter-day precision } & \multicolumn{2}{c|}{ Intra-day precision } \\
\cline { 2 - 4 } & Mean area (AU) & \% RSD & Mean area (AU) \\
\hline 300 & 2695 & 0.88 & 2713 \\
\hline
\end{tabular}

Table 4: Precision for the Sulbactam sodium $(n=6)$

\begin{tabular}{|l|l|l|l|l|}
\hline \multirow{2}{*}{$\begin{array}{l}\text { Conc. of the Sulbactam sodium } \\
\text { ng/ band) }\end{array}$} & \multicolumn{2}{|c|}{ Inter-day precision } & \multicolumn{2}{c|}{ Intra-day precision } \\
\cline { 2 - 4 } & Mean area (AU) & \% RSD & Mean area (AU) \\
\hline 1500 & 3395 & 1.54 & 3400 & 1.22 \\
\hline
\end{tabular}




\subsubsection{Robustness of the method}

Following the introduction of small deliberate changes in the mobile phase composition were done and effect on the results were examined. Mobile phase having different compositions were tried and chromatograms were run. The small change of $\pm 0.1 \mathrm{~mL}$ for each component of the mobile phase was done.

The robustness of the method was determined at three different concentration levels. The results are tabulated as under:

Table 5: Robustness testing

$(\mathbf{n}=3)$

\begin{tabular}{|c|c|c|c|c|c|c|}
\hline Parameter & $\begin{array}{l}\text { Conc. Level in ng } \\
\text { spot }^{-1} \text { of Ceftriaxone } \\
\text { sodium }\end{array}$ & $\begin{array}{c}\text { SD of Peak } \\
\text { response of } \\
\text { Ceftriaxone sodium }\end{array}$ & $\%$ RSD & $\begin{array}{l}\text { Conc. Level in } \\
\text { ng spot }^{-1} \text { of } \\
\text { Sulbactam } \\
\text { sodium }\end{array}$ & $\begin{array}{l}\text { Mean Peak } \\
\text { response } \\
\text { Sulbactam } \\
\text { sodium }\end{array}$ & $\%$ RSD \\
\hline \multirow{3}{*}{$\begin{array}{l}\text { Mobile phase } \\
\text { composition } \\
( \pm 0.1 \mathrm{~mL})\end{array}$} & 240 & 160 & 1.89 & 1200 & 84.4 & 1.69 \\
\hline & 300 & 170 & 1.92 & 1500 & 110 & 1.94 \\
\hline & 360 & 57.8 & 0.60 & 1800 & 42.6 & 0.66 \\
\hline \multirow{3}{*}{$\begin{array}{l} \pm 5 \% \text { variation in } \\
\text { mobile phase }\end{array}$} & 240 & 150 & 1.71 & 1200 & 75 & 1.59 \\
\hline & 300 & 174 & 1.96 & 1500 & 105 & 1.84 \\
\hline & 360 & 65 & 0.68 & 1800 & 50 & 0.88 \\
\hline
\end{tabular}

\subsubsection{Linearity}

A series of standard solutions were prepared from the standard stock solutions of Ceftriaxone sodium and Sulbactam sodium. Solutions were spotted on the TLC plate in the range of $2 \mu 1$ to $14 \mu$ l of ceftriaxone sodium and sulbactam sodium respectively. The corresponding concentrations were in the range of $0.2 \mu \mathrm{g} / \mathrm{spot}$ to $1.4 \mu \mathrm{g} /$ spot and $1.0 \mu \mathrm{g} / \mathrm{spot}$ to $7.0 \mu \mathrm{g} / \mathrm{spot}$ respectively. The linear Correlation coefficient for ceftriaxone sodium is 0.9998 and correlation coefficient for sulbactam sodium is 0.9953

\subsubsection{LOD and LOQ}

The limits of detection (LOD) and Limit of Quantitation (LOQ) were calculated from slopes of the calibration curve. The limit of detection and Limit of Quantitation obtained by this method for Ceftriaxone sodium and Sulbactam sodium are $\mathrm{LOD}=0.28 \mathrm{mcg}, \mathrm{LOQ}=0.859 \mathrm{mcg}, \mathrm{LOD}=5.226 \mathrm{mcg}$ and $\mathrm{LOQ}=15.838$ mcg respectively.

\subsubsection{Analysis of formulation}

Experimental HPTLC results of the amount of Ceftriaxone sodium and Sulbactam sodium in the dry powder Injectables expressed as a mg of label claim were in good agreement with the label claim.

The drug content in the unit was found to be $100.5 \%$ and $101 \%$ for Ceftriaxone sodium and Sulbactam respectively.

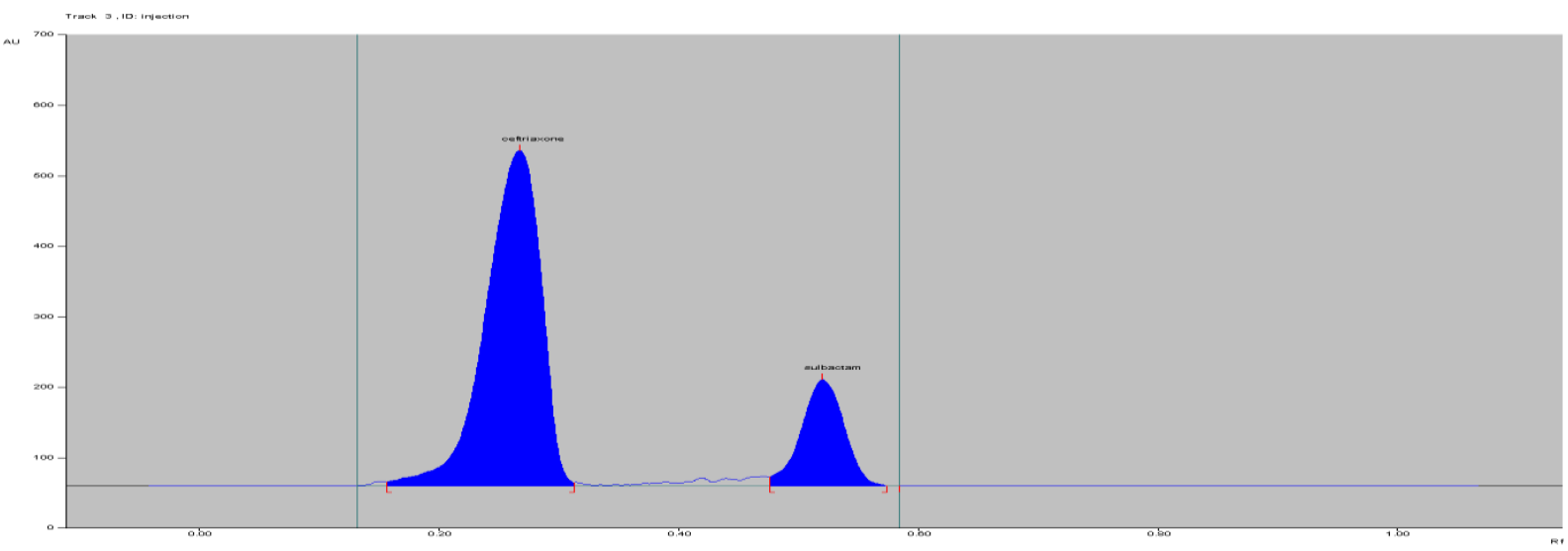

Figure 1. Densitogram of Ceftriaxone sodium $\left(\mathbf{R}_{\mathrm{F}} \mathbf{0 . 3 1}\right)$ and Sulbactam sodium $\left(\mathbf{R}_{\mathrm{F}} \mathbf{0 . 5 8}\right)$

\subsubsection{Conclusion}

HPTLC analysis is rapidly becoming popular in routine analysis due to its advantage of low operating costs, high sample throughput. This method can be used for simultaneous determination of Ceftriaxone sodium and Sulbactam sodium in routine analysis. 
It may be extended to the degradation study of the Ceftriaxone sodium and Sulbactam sodium and also for its estimation in plasma and other biological fluids.

The proposed HPTLC method is simple, accurate, economically chief and reproducible.

\section{Acknowledgements}

The Authors wish to express many thanks to Mr. Vikrant Tamse for providing the reference standards required for the research work. We also thankful to M/s Anchrom Testlab Pvt. Ltd. Mulund ( E) ,Mumbai400081 for providing their support to carry an Analytical work at their well established Laboratory.

\section{References}

[1]. Bradley JS, Wassel RT, Lee L, Nambiar S (April 2009). "Intravenous ceftriaxone and calcium in the neonate: assessing the risk for cardiopulmonary adverse events". Pediatrics 123 (4):

[2]. Budavari S, editor. The Merck index. 13th. Whitehouse Station. NJ: Merck \& Co; 2001. p. 335.

[3]. The United States Pharmacopoeia, $36^{\text {th }}$ Revision. Rockville, MD: U.S. Pharmacopoeial Convention, Inc; 2013.

[4]. British Pharmacopoeia. II. London: Her Majesty’s Stationary Office; 2007. p. 1965

[5]. Zhao W, Zhang Y, Li Q. Indirect spectrophotometric determination of sodium ceftriaxone with n-propyl alcohol-ammonium sulfate-water system by extraction floatation of copper(II) Clin. Chim. Acta.2008;391:80-848.

[6]. Granich GG, Krogstad DJ. Ion pair high-performance liquid chromatographic assay for ceftriaxone. Antimicrob. Agents Chemother. 1987; 31:385-388.

[7]. Al-Momani IF. Spectrophotometric determination of selected cephalosporins in drug formulation using flow injection analysis. J. Pharm. Biomed. Anal. 2001; 25:751-757.

[8]. El-Walily AFM, Gazy AA, Belal SF, Khamis EF. Quantitative determination of some thiazole cephalosporins through complexation with palladium (II) chloride. J. Pharm. Biomed. Anal.2000;22:385-392.

[9]. Patel SA, Patel NM, Patel MM. Spectrophotometric estimation of cefotaxime and ceftriaxone in pharmaceutical dosage forms. Indian J. Pharm. Sci. 2006;68:101-103.

[10]. Eric JS, Agbaba D, Zivanov-Stakic D, Vladimirov S. HPTLC determination of ceftriaxone, cefixime and cefotaxime in dosage forms. J. Pharma. Biomed. Anal. 1998;18:893-898.

[11]. Marini D, Balestrieri F. Determination of ceftriaxone by HPLC. Farmaco. 1986;41:172-176

[12]. Totir MA, Helfand MS, Carey MP, et al. (August 2007). "Sulbactam forms only minimal amounts of irreversible acrylate-enzyme with SHV-1 beta-lactamase". Biochemistry 46 (31): 8980-7

[13]. Singh GS (January 2004). "Beta-lactams in the new millennium. Part-II: cephems, oxacephems, penams and sulbactam". Mini Rev Med Chem 4(1): 93-109.

[14]. Goodman Gilman's, The Pharmacological basis of therapeutics, $10^{\text {th }}$ ed. McGraw-Hill: London, (2001); p.569-620.

[15]. Sanjay Mohan shrivastava, Rajkumar singh, and Abu Tariq, A novel HPLC method for simultaneousdetermination of Ceftriaxone and sulbactam in sulbacomax., Internationl journal of biomedical sciences. 2009, Volume 5, 10-15. 